\title{
Revisiting the public health-urban design nexus in the post-pandemic era
}

\author{
Mahyar Arefi ${ }^{1} \cdot$ Noha Nasser $^{2}$
}

Accepted: 20 October 2021 / Published online: 27 October 2021

(C) The Author(s), under exclusive licence to Springer Nature Limited 2021

That the global COVID-19 pandemic has literally changed life as we knew it, sounds more like a truism almost 2 years since its unprecedented rapid outbreak. Having said that, different fields and professions continue sharing new research contributions with the hope of gleaning important lessons from this challenging experience. Urban design and planning are not exceptions to the outpourings of these collective academic endeavors either, and can potentially provide important research outcomes to help policymakers, public authorities, and people in general, make more informed decisions.

The current issue of Urban Design International devotes three commentaries and four original research articles to this important topic. In a piece entitled "All change; Has COVID19 transformed the way we need to plan for a healthier and more equitable food environment?" Chang, Green and Cummins explore the post-pandemic role planning can play in improving public health. This commentary draws out some lessons from the food environments in Wales. The authors argue that home-bound, long-term lockdowns can exacerbate obesity. The rising trend of "dark" or "ghost kitchens" and dietary inequalities in a given community justify appropriate spatial and planning policies for uncertain futures. Exploring a similar nexus between public health and spatial planning, Louis Rice delves into the concept of "spatial medicine" in "After COVID-19: Urban design as spatial medicine." He warns that downplaying the role of urban design can jeopardize public heath, and impose losses of lives world-wide.

In another short commentary entitled "The Planners' response to COVID-19," Sue Manns underlines yet another relevant dimension of the interface between health, urban design, and planning. She underlines the significance of urban design and health experts in exploring new partnerships for healthy placemaking practices, including the

\footnotetext{
Mahyar Arefi

mahyararefi@gmail.com

Jundi-Shapur University of Technology, Dezful, Iran

2 Cardiff University, Cardiff, UK
}

government's role in providing necessary resources that could further accommodate such partnerships.

Against the backdrop of the three previous commentaries on the nexus between public health and urban design, the following full-length articles delve deeper into more specific empirical outcomes surrounding the COVID-19 pandemic. In "Lockdown in a disneyfied city: Kraków Old Town and the first wave of the Covid-19 pandemic," Anna Porębska et al., focus on the lockdown during the first wave of the COVID-19 in Krakow, Poland. Warning against hasty development decisions that might, among other things, jeopardize the amelioration of carbon-footprints by building more instead of less, the authors critically examine the Polish National Recovery Plans with a special emphasis on Krakow's historic city center known for its Disneyfied, Gothic, cathedral and "fairy-like architecture" that turned into a ghost town amidst the COVID-19 lockdown. On a larger scale, besides Disneyfication, the COVID-19 experience has unraveled the health and environmental inequalities in Poland. Thus, while warning against rampant deregulation or building more constructions that could inadvertently end up destroying the forests, or access to green space, the authors call for equitable, environmentally-responsible planning.

Another case study research in Madrid entitled "When a city must be a tree: rethinking the spatial approach to fighting epidemics based on the notion of 'intermediate confinement'," Carpio-Pindo et al., address the potential advantages of the familiar "city as a tree" analogy as an effective hierarchical urban system in dealing with lengthy lockdowns. Reporting on their empirical analysis of the lockdown in Madrid, they propose an "intermediate confinement" model which falls somewhere between two familiar extreme options: the city as a typical open and accessible lattice-like system involving the city center, local centers and homes on the one hand, and the total lockdown of the entire system, on the other. This in-between model allows limited access between local centers and homes giving people more leeway 
compared to complete lockdowns experienced during the COVID-19 pandemic.

Miranowicz, et al., on the other hand, conduct a comparative case study of cities from Austria, France, and Poland during the times of confinement. Placing emphasis on yet another aspect of local planning and design, the authors shed some light on what they call "essential facilities" in "Space and spatial practices in times of confinement; Evidence from three European countries: Austria, France and Poland." Somewhat similar to the previous research, the authors report and highlight the common virtues of "new" and "essential facilities" at the local level. These outcomes celebrate the roles of local, small facilities, i.e., local shops and stores as opposed to big shopping centers or megamalls during pandemics and lengthy lockdowns. The same thing applies to local public green spaces as well. Of particular importance to authors is the role urban design practices can play in finding middle-grounds and effective solutions that help people to better cope in times of hardship.

The last article "Covid-19 as an "invisible other" and socio-spatial distancing within a one-metre individual bubble" by de Rosa and Mannarini revisits the symbolic meanings of public space in everyday life. While seeing the COVID-19 pandemic as a global challenge, the authors also lay out the potential opportunities such a collective calamity could generate. Among other things (i.e., improving the green infrastructure of cities), they question the term "social distancing" and instead, suggest "physical" or "spatial distancing" as a more appropriate term. They argue that times of hardship, while forcing physical segregation, would not necessarily deprive people from maintaining or taking advantage of their social connections. To support this argument, they discuss "culture," "well-being," and resilience" as three positive attributes associated with social connections.

Publisher's Note Springer Nature remains neutral with regard to jurisdictional claims in published maps and institutional affiliations. 